\title{
Daily Life Experience of Institutionalized Elderly People
}

\author{
Buthaina Hameed Hassan Al Asfoor \\ Royla College of Surgeon in Ireland, Medical University of Bahrain, Manama, Kingdom of Bahrain
}

\begin{abstract}
There is a continuous increase in the number of elderly people moving in to residential care facility in the Kingdom of Bahrain. Admission in to the residential facility perceived in Bahrain society as stigma, rejection for elders by their family members and a violation to Bahrain family values. Many adverse effects of institutionalizing elderly people were reported in literatures. This study aimed to explore the lived experience of institutionalized elderly people in order to generate appropriate interventions to smooth the transition in to the residential facility. A qualitative, phenomenological approach was used. The study was carried in one of the elderly residential health care institutions in the kingdom of Bahrain. The sample composed nine participants, were interviewed and audio recorded. The five themes emerged from the data analysis included: no choice, no freedom, killing routine, home of negligence, and elderly refuge. The conclusions involved implication for clinical practice, education and management. Future research in the same area was recommended.
\end{abstract}

Key words: Daily experience, institutionalization, residential care.

\section{Introduction}

Life expectancy increased dramatically all around the world. In Bahrain, although the percentage of elderly population remained static during the past ten years, the number of admission in to residential facilities dramatically increased. The family had traditionally been the primary health care provider for elderly people in Bahrain. Admission to residential care represent for elderly stigma and loss of value. In addition, many health adverse consequences had found to be associated with elderly people transition. This study assumed to be significant to nursing practice because the negative effects of elderly institutionalization could be preventable through soothing the transition process. The transition process considered a unique experience that can be understood by elders' stories and descriptions of this event, which can be achieved through this study. The results of this study is expected to help in developing a better health care planning for relocated elderly people in Bahrain. The most important objective of this study is to reinforce coping skills and help the older person find

Corresponding author: Butaina Hameed Hassan Al Asfoor, M.Sc., nursing supervisor, research field: gerontology. E-mail: bbalasfoor@hotmsail.com. new strategies in the new living situation.

\section{Methodology}

Naturalism was used as the most relevant paradigm of this study, and phenomenology was used as the most appropriate research approach. The setting of the study was in one of the elderly residential health care institutions in Bahrain. The purposive sample included nine participants, five males and four females. Inclusion criteria were all those residents for at least two months at the health care institution, and the elderly people who are able to describe their situation. Exclusive criteria were recently admitted elderly who lived less than two month at the residential institution, and elderly who are unable to describe their situation. The researcher followed strictly ethical approval by obtaining two institutional ethical reviews, assessing mental legibility for the participants, providing written/verbal information to the participants and obtaining informed consent from each participant to be interviewed and tape-record. It is believed that standards related to credibility, and authenticity was met. Data was collected by conducting a conversational, semi-structural, audio recorded and interviews. Each individual was interviewed 
individually between $30 \mathrm{~min}$ to $45 \mathrm{~min}$.

\section{Analysis}

The analysis process allowed emerging themes to be identified. This included reading the entire transcripts, initial coding of interviews and identification of five themes. The process of themes identification was done by using Giorgi (1985) four steps of qualitative data analysis [1].

\subsection{Demographic and Personal Information}

The sample represented nine participants, five male and four female, mean age 72.7 years old. All participants suffered from chronic diseases such as diabetes mellitus, ischemic heart disease, hypertension, arthritis, and bronchial asthma. The shortest residential duration was nine months and the longest duration was six years. Refer to Table 1 to view participant demographic data, diagnosis, physical dependency level, and residential duration.

\subsection{Emerging Themes}

The categorization strategy was carried out to identify commonalities and differences in the data depending on the number of occurrence of the particular category in each transcript, which indicated the importance of the category, as expressed by the participants. Elderly experiences of residential life became the basis for the theoretical ideas presented in the following themes: no choice, no freedom, killing routine, home of negligence, and elderly refuge. A description of each theme, supported by participants' statements will be elaborated in the discussion. Table 2 illustrates the categorization mechanism leading to the identification of five themes.

\section{Discussion}

\subsection{No Choice}

All participants expressed that they had no choice in regards to their relocation in elderly care institution, but in a different ways. "I was forced to enter here and I hope I can go out one day and live my life again. Looking to go out again is just like prisoner who looks for rope to climb and go out", "My son brought me to elderly home. He said that the government provide home for cases like me. I didn't reject the idea because I don't have another choice".

Few elderly people actively plan to be in a care home. They find themselves living in one because of a crises in their health, or because somebody else persuade them [2-5]. Elderly people feared the residential care institutions and view them as dumping place [6, 7].

Table 1 Summery of participants' demographic and personal information.

\begin{tabular}{|c|c|c|c|c|c|c|}
\hline Code & Age & Sex & Medical diagnosis & Residential duration & $\begin{array}{l}\text { Admission decision } \\
\text { maker }\end{array}$ & Reason for admission \\
\hline $\mathrm{T} 1$ & 63 & M & $\begin{array}{l}\text { DM, HTN, Cataract } \\
\text { Arthritis, Depression }\end{array}$ & One year \& nine months & Client & Homeless \\
\hline $\mathrm{T} 2$ & 84 & M & Bronchial Asthma & One year \& six months & Health professional & $\begin{array}{l}\text { Homeless } \\
\text { Lack of care providers }\end{array}$ \\
\hline T3 & 87 & M & Poor vision & Two years \& two months & Son & $\begin{array}{l}\text { Living alone } \\
\text { Lack of care providers }\end{array}$ \\
\hline $\mathrm{T} 4$ & 67 & M & HTN, Poor vision & Two years \& three months & Health professional & $\begin{array}{l}\text { Homeless } \\
\text { Lack of care providers }\end{array}$ \\
\hline T5 & 64 & M & Benign prostate, DM, HTN & Two years \& two months & Health professional & $\begin{array}{l}\text { Living alone } \\
\text { Lack of care providers }\end{array}$ \\
\hline T6 & 64 & $\mathrm{~F}$ & DM, HTN & Nine months & Nephew & $\begin{array}{l}\text { Living alone } \\
\text { Lack of care providers }\end{array}$ \\
\hline $\mathrm{T} 7$ & 64 & $\mathrm{~F}$ & $\begin{array}{l}\text { Sickle cell disease, DM, } \\
\text { HTN , depression }\end{array}$ & $\begin{array}{l}\text { Three years \& seven } \\
\text { months }\end{array}$ & Brother & Lack of care provider \\
\hline T8 & 78 & $\mathrm{~F}$ & IHD, Osteoporosis & One year \& five months & Brother & Lack of care provider \\
\hline T9 & 84 & $\mathrm{~F}$ & DM, HTN, IHD & Six years & Client & Living alone \\
\hline
\end{tabular}

M: Male; F: Female; DM: Diabetes mellitus; HTN: Hypertension; IHD: Ischemic heart disease. 
Table 2 Summery of the categorization mechanism leading to the identification of five themes.

\begin{tabular}{|c|c|}
\hline Sub-themes & Emerging themes \\
\hline \multicolumn{2}{|l|}{ Lack of care providers } \\
\hline \multicolumn{2}{|l|}{ Loss of health } \\
\hline Loss of productivity & No choice \\
\hline \multicolumn{2}{|l|}{ Fear of outside world } \\
\hline \multicolumn{2}{|l|}{ Saving dignity } \\
\hline \multicolumn{2}{|l|}{ Nobody is listening } \\
\hline \multicolumn{2}{|l|}{ Restricting role and regulation } \\
\hline Humiliation & No freedom \\
\hline \multicolumn{2}{|l|}{ Lack of privacy } \\
\hline \multicolumn{2}{|l|}{ Lack of autonomy } \\
\hline \multicolumn{2}{|l|}{ Routine } \\
\hline \multicolumn{2}{|l|}{$\begin{array}{l}\text { Limitation in activities } \\
\text { Boredom }\end{array}$} \\
\hline Boredom & niming routme \\
\hline \multicolumn{2}{|l|}{ Loneliness } \\
\hline \multicolumn{2}{|l|}{ Nobody is listening } \\
\hline Health worker carelessness & Home of negligence \\
\hline \multicolumn{2}{|l|}{ Lack of touch } \\
\hline $\begin{array}{l}\text { Availability of accommodation and } \\
\text { services }\end{array}$ & Elderly refuge \\
\hline Building new relationships & \\
\hline
\end{tabular}

Participants expressed a hidden helplessness in term of their relocation. For instance, their long term illnesses, physical dependency, and lack of care providers were main reasons for their relocation and not their own wishes. "I entered here because I was sick", “The reason I came here was that I'm not walking anymore and I need someone always with me to attend my needs. My brother is telling here is better for me, and they will provide me with a better care. He told me that if I could walk again he would keep me at home". Some participants expressed their refusal to be burden on others, and deciding to relocate as a way to save their dignity. "Once I was in my nephew house, setting in their living room and hearing them inside the kitchen discussing something. His wife said to him I don't want your aunty to live here, and my nephew didn't say anything about it, and kept quite. I felt hurt because that was only a visit to my nephew house, and I didn't intend to live there, and the wife couldn't beer me! The worse was the response of my nephew, instead of clarifying to his wife my position, as the eldest aunty, and the next after his mother; he was just like agreeing with her. I don't want any mercy from these people. I prefer to save my dignity. God mercy is better.”. In a similar view [8], the residents may feel that the best they had left to offer loved ones was freedom from the burden of their care.

Some participants expressed fearing the outside world, where they were unable to live safely alone or trust anybody. "Actually I'm afraid to go out of here, because I don't have place to go and I don't have anyone to look after me.” A similar result [9] found where participants expressed feeling very comfortable and safe when recalling their worries before the admission about having home accidents.

A group of researchers identify health deterioration to be predictors for elderly people relocation [2, 3, 10]. Residents may face the challenge of coping with the loss of independence, reduced physical abilities, and feelings of isolation, anxiety, depression, and helplessness, all of which may result in increase in their morbidity and mortality [11-13]. Anyhow, there is a view [14] that successful aging as a successful adaptation of the individual to changes during the aging process. Positive perception of elderly residents to themselves might be an important factor to adjustment the residential life, regardless their health status particularly in dealing with relocation distress, having self-worth and participating in group life [7]. These findings imply that elderly people may successfully age in residential facility if their adaptation capability was empowered. Positive perception of elderly residents to themselves might be an important factor to adjustment the residential life, regardless their health status particularly in dealing with relocation distress, having self-worth and participating in group life [7]. These findings imply that elderly people may successfully age in residential facility if their adaptation capability was empowered.

A group of researchers had studied the voluntary and involuntary relocation and their influence in elderly people adjustment to residential life $[12,15,16]$. In this study, despite the variations in reasons for admission, admission decision makers, and elderly involvement in the decision, the researcher came up with the fact that there was no real voluntary relocation for all 
participants. Comments that were given by participants who made the decision revealed that it was taken in a situation where they perceived that there were no other alternatives. Relocating to residential facility was seen by elderly participants to be, at best, a forced choice [8].

\subsection{No Freedom}

Elderly people expressed that they had lost their freedom by restricting them with the institutional rules and regulations. For instance elderly cannot go out the centre without accompaniment, registration of the accompanied person, and duration of the leave. "I'm in a jail. I don’t feel free as before”, “In winter time we should stay only inside, and we can't go out in the garden. We should have in door garden for such times”. The old person in Bahrain community was referral for advices and wisdoms and privileged with respect. This position for elderly people had changed. Elderly role as spouse, parents and grandparents has diminished, as children and grandchildren reverse roles and begin to treat them as the children. The former roles would exacerbate this devalued sense of self [8]. Living with rules and regulations was also found to be a strong barrier to residential life adjustment and tend to exacerbate feelings of abandonment, leading to poorer prognoses [9, 17-19]. However, a study [17] regarded rule and regulation as "law of the country", as Chinese elderly participants expressed their understanding about meeting collective needs rather than individual needs. Traditionally, they prefer eating together as a big family, and their past experience in sharing a flat with many families had helped them accommodate the residential need of sharing common facilities with ease.

One attribute of autonomy is involvement of residents in decision making and negotiating care planning [20]. Elder participants expressed that their autonomy had been reduced after their relocation, in term of deciding for themselves and telling their opinions and suggestions. "I can’t take shower the time that I wish, they used to wake us early morning and give us shower, and they will not leave the decision for us in regard to bath timing.” Elderly people who feel that they have at least been given the opportunity to be involved in decisions could perceive themselves to have more control after their relocation [8].

Additionally, elders may feel losing autonomy because of the disruption of their already established daily routine and relationships before admission [9]. Elderly lack of control started when feeling forced to leave home and enter a residential facility along with losing their identity and possessions such as losing home, neighborhood, and contact with friends and family $[8,17]$. Elders may feel the loss is not so much for the material objects but rather for what they symbolized and the memories that they evoked [8]. The great differences in living arrangement before and after admission, as well as the lack of previous residential life experiences were identified as major causes of a painful transition experience [17]. "I have travelled to many countries before. Out is different. I can go everywhere and see people again. I can go to my favorite coffee shops and set with my friends. I missed the radio sound in there. I'm not annoyed to be here, but of course I prefer outside, although I can't see well."

Also, elderly losing of autonomy was expressed as lack of privacy, by elderly residents not feeling comfortable with their roommates. "Sometimes I quarrel with my roommate because we want different channel on TV, or because I want the light on, when I am praying, and she doesn't.” The elders may feel inconvenient in the new environment together with the sick roommates, resulted in feeling very frightened and uneasy with the transition [9]. "I don't like keeping me with confused patient who are out of their mind. Some of them scream, laugh loudly beet themselves like crazy people and curse others. I can't sleep at night time because they used to disturb me.”

\subsection{Killing Routine}

Living in a routine was one important concern for elderly residents in this study. They had explained 
feeling boring of similar daily activities, and living a routine life, was just like living in a cycle that ends where it starts. "There are limitations in inside activities. Every morning they used to take us to the main hall, have lunch, set for a while watching TV, having dinner and then back again to bed." "I remain alone even though I'm setting with all, and I feel bored.” Elderly people previous roles as a home-maker and breadwinner have gone, along with employment and home, leaving in elders' life big space and loneliness [8].

Although the center in which the study was connected provides indoor and outdoor activities, it was recognized by participants as few and repeated. Such activities were gathering in TV hall, occasional celebrations and scheduled picnic. The place lack occupational and recreational therapy. In contrast, in a study conducted to investigate an elderly residence occupation activities [19], 20 programs were available in the residential facility in which the study held, including pet therapy, exercise, cooking classes, residents and family councils, church services, access to pastoral care, and interaction with preschoolers at an on-site daycare and occasional visiting entertainment. Residents usually desire to have more activities in their residence [21]. One participant suggested changing the routine by introducing new activities, "I know many elderly who have handicraft talent such as carpentry, pottery making, and sewing, but nobody offer them handcraft activities. If we were engaged in such activities the time will run fast and we would feel productive and worthy."

A researcher [7] identified satisfaction with the facility as a significant predictor of adjustment. The increase in routinization in daily life is associated with decreases the adjustment abilities of the elderly residents [22]. A group of researcher emphasized that activity programs improve elderly well being, empower residents in their new environment and foster the adjustment process [15, 21, 23-28]. Specifically, activities that promoted social involvement was reported to be significant in leading healthy life and enhance feeling good about oneself, even if elderly people are experiencing illness and disability [4]. In residential facility, elderly people may spent less time in social events and community interactions, which were major part of their life. For some, this increases feeling of isolation and loneliness and decreases their satisfaction with the activities provided [29].

There has been very strong support for resident's relations with staff and peers as the most important aspect of their quality of residential life [7, 19, 30-32]. The relocated elderly losses such as home routines, sense of independence, physical and communicative abilities, made any relationship gained, critical for their sense of self worth [19]. Elderly residents relay on family members for connection to their previous lives, and for those without family or friends, the relay on staff and peers [19]. Some participants in this study verbalized adjusting being away from loved once. Hence, relationships with staff and peers seemed to be more important, to participants in this study, than the familial relationships. Similarly, it was found that the frequency visit from family was not associated with adjustment to nursing home life [7]. Rather, the social support from the people inside the facility, staff and other residents, is more influential to adjustment.

\subsection{Home of Negligence}

Elderly participants explained that negligence took the form of ignoring elderly residents, poor communication and delay in responding to their needs. "It is like slow death here because of staff negligence" stated by one resident. "They never ask us anything about our opinion, and if we talk or suggest, no one would listen or react. For example nobody will ask whether food is good or not, or do we like it or not. I suggested greenhouse, but nobody bother about it. If I complain about anything happened during shifts duty to the administration, they would simply tell that it is not their responsibility, because they were not on duty at that time. Who should follow our problems and 
concerns?” It was found that elder residents complain that staff couldn't understand their needs [9]. They expressed feeling as if they have become non-person, not because of their inability to do things, but because they are dependent on waiting for staff to take their concerns. Participants considered lack of touch as a type of negligence, and used the word unethical to label this behavior. "Nurses here will depend on aids in direct contacting elderly, and will not touch the patients at all. They treat elderly like dirty people who shouldn't be touched, is this ethical? I do not call them "sisters", but I call their names, because they don't deserve this nomination.” Furthermore, some participants expressed that they had been verbally abused by care providers. "Staff here sometimes rude when dealing with us, but if any staff talk to me harshly I just forgive them, this makes me live peacefully," "There are good and bad nurses. Bad nurses are not treating us well, I mean verbally they are harming us, and never use good words." Elderly residents generally were reported by group of researcher to be prone for abuse within the residential facility as a result of their frailty [33, 34]. Such abusive behaviors were reported to be mostly disrespectful behaviors, humiliation and negligence [33]. Although participants, in this study, acknowledged availability of good services, they verbalized that these services will never compensate good treatment. "It's good to have place to live and food to eat, it's clean here, they are cleaning the floor with disinfectant daily, but all this will not compensate the good treatment for elderly."

A group of researcher had emphasized that communication is vital for care provision especially for assessing the specific needs of elderly patients [9, 30, 35, 36]. Nurses should communicate knowledge, understanding, caring, kindness, sociability, and intuition [9]. Staff-patient superficial relationship may form because elderly may view staff as rulers of the country [17]. Furthermore, the residents may feel that they are merely a list of tasks for staff to attend [9]. Some residents may turn between the need for attention and feeling guilty in increasing work pressure on staff [19]. Such conflict may increases anxiety, feeling of helplessness, and result in a loss of personhood and self value of residents [19]. They, therefore, may not actively seek to establish relations with staff and reveal their difficulties in settling in.

However, some other residents verbalized having good relationships with health care providers, and commented that staff were caring and treating them nicely. "Health workers here are very nice, they treat me well.” Anyhow, a researcher [37] clarified getting high percentage of positive residents' responses when assessed elderly people residential care satisfaction, which did not correlate with the observation because some residents were reluctant to criticize staff or their behaviour. The residents may cooperate to avoid being seen as trouble maker [19].

\subsection{Elderly Refuge}

Elderly were generally satisfied about services provided such as food, clothing, bathing schedule, medical treatment, and inside and outside activities. “Aids are giving us bath daily early morning, they dress and groom us, keep us on chair and gather us in the main hall to take breakfast and lunch together and then take us back to bed. I generally like the daily schedule here." Some participants said that the center was better than the outside world. One liked being there because he was alone outside, whereas in the center he was able to meet other elderly people to talk to them. Elder persons living alone are more likely to look for residential placement as a strategy to gain social contact with others [9]. Therefore, for elders how were living alone before the admission, positive consequences of the admission were anticipated. "I am very happy here. I was living alone and have nothing to do, now I have many relationships, and we used to gather and chat daily.” A researcher [17] found that the average waiting time in Hong Kong for nursing home placement is more than two years, and majority of elders' Chinese people consider themselves very lucky 
to have been given a place in a nursing home. They believed that they should, therefore, be thankful and try to be complainant to nursing home life as much as possible.

Some other elders' statements implied that they accepted living in the center with a sense of hopelessness. "I do not mind being here, and I believe that dying here or there is the same because death is the same anywhere. I'm in the hand of God." Generally, when people move from a place to another, there is a sense of future, but for elderly people moving to long term care meant the end of line [8]. They could no longer think in term of future. When elderly people feel that they have lost everything that they have spent their life building, and they know that they have neither the time nor the capacity to start again, they cannot perceive the future [8].

Anyhow, it was shown that the elderly residents are able, within the institutional environment, to construct the life in world of their own [17]. The elderly people may find new ways to live within the new environment even if they are totally not accepting their situation. This complex process involves a struggle to regain a life that is as close as possible to that lived before placement to residential facility [17]. Participants of this study expressed using their effort to gain understanding of every aspect of residential life. They explained observing very closely how other residents acted, behaved and spent their days, and identified them as a role model to help settled them in to the residential facility. The author had noticed that, for the physically able participants, who are unable to live independently in the community for social reasons, shelter and food were the main forms of care provision needed. Whereas more frail and dependent older people, who are unable to live independently in the community for physical reasons, activity of daily living were the form of care provision needed.

Regardless the variations in the elders' needs and services provided, the residential facility seemed to refuge them. It is a place that substitutes the community in term of provision of basic life needs, rehabilitation, and socializing, but it does not necessarily be like home. A researcher found that most elderly define elderly care facility as their second home that is almost like their first home except that elders will not live with their families [17]. While elderly participants of the current study believed that this placement was unavoidable, it was an important source of conflict in their later years.

\section{Conclusions}

In conclusion, the researcher intends to develop recommendations that stand for the five developed themes:

(1) Recommendation for clinical practice:

Nurses must develop a comprehensive assessment for elderly residents, prior, after the admission and throughout their residency to assess their adjustment in the new environment;

Nurses must plan and reinforce appropriate coping strategy for each elderly resident;

Nurses must promote effective communication with elderly people;

Nurses must consider ethical issues and adhere to code of professional conduct of the residential institution to preserve patients' rights and dignity.

(2) Recommendation for education:

Health care planner must introduce educational programs for both health care providers and elderly people in order to educate, orient and prepare them regarding the transition process.

(3) Recommendation for management:

Health care planner must plan for gradual relocation process to help elderly people and their families accept and adjust the residential life;

Health care planner must maintain adequate activities within the residential facility, in order to maintain elders' productivity, sense of worthiness, and break the life routine;

Health care planner must develop roles and regulations that maximize the elders' autonomy, as much as possible, within the residential facility; 
Health care planner must develop policy and procedures that are coherent with the elder residents' needs, which were represented through the five emerged themes;

Health care planner must assess elderly quality of life within the residential facility by auditing the specific areas of needs represented through the five emerged themes.

(4) Recommendation for research:

It is worthy to study the transition to residential life with older resident whose admission is expected to be temporary. It is assumed that the experience will differ for elderly people whom admissions are temporary.

While this investigation focused on understanding resident's point of view, future research could extend understanding the issue of elderly residential life experience from nurses and significant others points of view.

It would be of value to compare the experience of those who live with families before their transition and those who live alone.

Future research may focus on studying each of the five emerged theme by using quantitative approaches to investigate variables such as gender, marital status, and health condition to validly and reliably sample elderly population.

\section{References}

[1] D.F. Polit, C.T. Beck, Essentials of Nursing Research: Methods, Appraisal, and Utilization, 6th ed., Lippincot Williams \& Wilkins, USA, 2006, pp.270-300.

[2] M. Henwood, The good life for older people, Community Care 1831 (2010) 30-32.

[3] R.J.A. Chou, Willingness to live in eldercare institutions among older adults in urban and rural china: A nationwide study, Aging and Society 30 (4) (2010) 583-609.

[4] B. Horner, D.P. Boldy, The benefit and burden of aging in place in an aged care community, Australian Health Review 32 (2) (2008) 356-366.

[5] R.A. Johnson, V.B. Schwiebert, P.A. Rosenmann, Factors influencing nursing home placement decisions: The older adult's perspective, Clinical Nursing Research 3 (3) (1994) 269-281.

[6] P.J. Biedenharn, J.B. Normoyle, Elderly community residents' reactions to the nursing home: An analysis of nursing home-related beliefs, Gerontologist 31 (1) (1991) 107-115.

[7] G.E. Lee, Predictors of adjustment to nursing home life of elderly residents: A cross-sectional survey, International Journal of Nursing Studies 47 (8) (2010) 957-964.

[8] R. Nay, Nursing home residents' perceptions of relocation, Journal of Clinical Nursing 4 (5) (2005) 319-325.

[9] D.T.F. Lee, Transition to residential care: Experience of elderly Chinese people in Hong Kong, Journal of Advanced Nursing 30 (5) (1999) 1118-1126.

[10] P.S. Mueller, C.C. Hook, K.C. Fleming, Ethical issues in geriatric: A guide for clinicians, Mayo Clinic Proceedings 79 (4) (2004) 554-562.

[11] N.G. Castle, Relocation of elderly, Medical Care Research Review 58 (3) (2001) 291-333.

[12] M.S. Lantz, E.N. Buchalter, L. McBee, The Wellness Group: A novel intervention for coping with disruptive behavior in elderly nursing home residents, Gerontologist 37 (4) (1997) 551-556.

[13] S.V. Kasl, Physical and mental health effects of involuntary relocation and institutionalization on the elderly, American Journal of Public Health 62 (3) (1972) 377-384.

[14] M. von Faber, A. Bootsma-van der Wiel, E. van Exel, J. Gussekloo, A.M. Lagaay, E. van Dongen, et al., Successful aging in the oldest old: Who can be characterized as successfully aged?, Arch. Intern. Med. 161 (22) (2001) 2694-2700.

[15] J. Rodin, E.J. Langer, Long-term effects of a control-relevant intervention with the institutionalized aged, Journal of Personality and Social Psychology 35 (12) (1977) 897-902.

[16] N. Bourestom, S. Tars, Alteration in life patterns following nursing home relocation, Gerontologist 14 (6) (1974) 506-510.

[17] D.T. Lee, J. Woo, A.E. Mackenzie, The cultural context of adjusting to nursing home life: Chinese elders' perspective, The Gerontologist 42 (5) (2002) 667-675.

[18] G. Dooghe, L. Vanderleyden, F. Van Loon, Social adjustment of the elderly residing in institutional homes: A multivariate analysis, International Journal of Aging and Human Development 11 (2) (1980) 163-176.

[19] D.T. Lee, Residential care placement: Perceptions among elderly Chinese people in Hong Kong, Journal of Advanced Nursing 26 (3) (1997) 602-607.

[20] C. Welford, K. Murphy, M. Wallace, D. Casey, A Concept analysis of autonomy for older people in residential care, Journal of Clinical Nursing 19 (9-10) (2010) 1226-1235.

[21] I. Andersson, E. Pettersson, B. Sidenvall, Daily life after moving in to care home-Experiences from old people, relatives, and contact persons, Journal of Clinical Nursing 16 (9) (2006) 1712-1718. 
[22] K.F. Smith, V.L. Bengtson, Positive consequences of institutionalization: Solidarity between elderly parents and their middle-aged children, Gerontologist 19 (5 Pt 1) (1979) 438-447.

[23] S.H. Chang, M.C. Fang, H.Y. Chang, Enhancing three bliss concepts among nursing home elders in Taiwan, Journal of Clinical Nursing 19 (5-6) (2010) 682-690.

[24] S. Ciairano, M.E. Liubicich, E. Rabagkietti, The effects of a physical activity pregame on the psychological wellbeing of older people in a residential care facility: An experimental study, Aging and Society 30 (4) (2010) 609-626.

[25] C. Knight, S.A. Haslam, C. Haslam, In home or at home? How collective decision making in a new care facility enhance social interaction and wellbeing amongst older adult, Aging and Society 30 (8) (2010) 1393-1418.

[26] M.M. Tse, Therapeutic effects of an indoor gardening program for older people living in nursing home, Journal of Clinical Nursing 19 (7-8) (2010) 949-958.

[27] N. Scarmeas, G. Levy, M.X. Tang, J. Manly, Y. Stern, Influence of leisure activity on the incidence of Alzheimer's Disease, Neurology 57 (12) (2001) 2236-2242.

[28] T.J. Hicks, Spirituality and the elderly: Nursing implications with nursing home residents, Geriatric Nursing 20 (3) (1999) 144-146.
[29] N. Fessman, D. Lester, Loneliness and depression among elderly nursing home patients, International Journal of Aging and Human Development 51 (2) (2000) 137-144.

[30] K. McDowell, More life in their years, Long Term Living 57 (2008) 46-48.

[31] J.E. Bitzan, J.M. Kruzich, Interpersonal relationships of nursing home residents, The Gerontologist 30 (3) (1990) 385-390.

[32] L. Wells, G. Macdonald, Interpersonal networks and post-relocation adjustment of the institutionalized elderly, Gerontologist 21 (2) (1981) 177-183.

[33] M. Cohen, S. Halevy-Levin, R. Gagin, D. Priltuzky, G. Friedman, Elder abuse in long-term care residences and the risk, Aging and Society 30 (6) (2010) 1027-1040.

[34] K. Pillemer, D.W. Moore, Abuse of patient in nursing homes: Findings from a survey of staff, Gerontologist 29 (3) (1995) 314-320.

[35] S.H. Yeh, L.W. Lin, S.K. Lo, A longitudinal evaluation of nursing home care quality in Taiwan, Journal of Nursing Care Quality 18 (3) (2003) 209-216.

[36] S.J. Chang, K.J. Lee, I.S. Kim, W.H. Lee, Older Korean people's desire to participate in health care decision making, Nursing Ethics 15 (1) (2008) 73-86.

[37] A. Pearson, S. Hocking, S. Mott, A. Riggs, Quality of care in nursing homes: From the resident's perspective, Journal of Advance Nursing 18 (1) (1993) 20-24. 